\title{
Dietary predictors of serum total carotene in low-income women living in São Paulo, south-east Brazil
}

\author{
Luciana Y Tomita ${ }^{1}$, Lana C Almeida ${ }^{1}$, Cecília Roteli-Martins ${ }^{2}$, Vania D'Almeida ${ }^{3}$ and \\ Marly A Cardoso ${ }^{1, *}$ for the BRINCA Study Teamt \\ 'Department of Nutrition, School of Public Health, University of São Paulo, Av. Dr Arnaldo 715, 01246-904 \\ São Paulo, SP, Brazil: ${ }^{2}$ Hospital Leonor Mendes de Barros, São Paulo, Brazil: ${ }^{3}$ Health Science Department, \\ Federal University of São Paulo, São Paulo, Brazil
}

Submitted 1 February 2008: Accepted 5 February 2009: First published online 1 April 2009

\begin{abstract}
Objective: Dietary intake and nutritional status of antioxidant vitamins have been reported to protect against some cancers. The objective of the present study was to assess the correlations between serum levels of carotenoids (including $\beta$-, $\alpha$ - and $\gamma$-carotene), lycopene, retinol, $\alpha$ - and $\gamma$-tocopherols, and dietary intakes estimated by an FFQ, among low-income women in the Brazilian Investigation into Nutrition and Cervical Cancer Prevention (BRINCA) study.

Design: Cross-sectional study of data for 918 women aged 21-65 years participating in the BRINCA study in São Paulo city. Multiple linear regression models were used with serum nutrient levels as the dependent variable and dietary intake levels as the independent variable, adjusted for confounding factors.

Results: In energy-adjusted analyses, the intakes of dark green and deep yellow vegetables and fruits (partial $R^{2}=4 \cdot 8 \%$ ), total fruits and juices (partial $R^{2}=1 \cdot 8 \%$ ), vegetables and fruits (partial $R^{2}=1 \cdot 8 \%$ ), carrots (partial $R^{2}=1 \cdot 4 \%$ ) and citrus fruits and juices only (partial $R^{2}=0 \cdot 8 \%$ ) were positively correlated only with serum total carotene levels, after adjusting for serum total cholesterol concentration, age, hospital attended, smoking status, BMI and presence of cervical lesions. Multiple-adjusted serum levels of carotenoids were positively correlated with intake quartiles of dark green and deep yellow vegetables and fruits and total fruits and juices independent of smoking status.

Conclusions: The intake of specific fruits and vegetables was an independent predictor of serum total carotene levels in low-income women living in São Paulo.
\end{abstract}

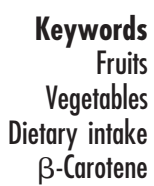

Several lines of evidence suggest that fruits and vegetables (F\&V) convincingly decrease the risk of CVD and probably protect against some cancers (mouth, pharynx, larynx, oesophagus and stomach) ${ }^{(1)}$. In addition to other strategies to prevent diet-related chronic diseases (i.e. obesity, diabetes mellitus, CVD, hypertension, stroke and some cancers), the WHO recommends increasing the consumption of F\&V to a minimum of $400 \mathrm{~g} / \mathrm{d}$. The protective effects of high $\mathrm{F} \& \mathrm{~V}$ intake against the abovementioned chronic diseases can possibly be explained by the reduction of total energy intake, the presence of blood pressure-lowering substances (K and phytochemicals), and the protection against reactive oxidants ${ }^{(2)}$. Carotenoids and tocopherols are natural antioxidants present mainly in F\&V among other dietary sources. Overall, 600 carotenoids have been isolated from natural

$\dagger$ See Appendix for list of members of the Brazilian Investigation into Nutrition and Cervical Cancer Prevention (BRINCA) Study Team. sources, including pro-vitamin A carotenoids ( $\alpha$-carotene, $\beta$-carotene and $\beta$-cryptoxanthin) ${ }^{(3)}$.

It has been shown that populations may have different plasma carotenoid profiles according to the type and amount of F\&V consumed and other demographic factors $^{(4)}$, such as income and educational level ${ }^{(5-7)}$. Many epidemiological studies show that diet quality follows a socio-economic gradient, since socio-economic status is likely to affect all aspects of energy balance from access to healthy foods to opportunities for physical activity ${ }^{(8)}$. Many studies carried out in developed countries have found correlations between serum vitamin concentrations (carotenoids, lycopene, tocopherols) and dietary factors $^{(5,6,9-13)}$. Dietary intake of F\&V has been described as a good predictor for some biomarkers ${ }^{(4,14-16)}$. However, only a few studies have been conducted in low-income individuals in both developed ${ }^{(7,17,18)}$ and developing nations ${ }^{(19-21)}$. The results of these studies should be carefully interpreted due to small sample size ${ }^{(19,20)}$ or 
methodological limitations related to the use of a nonvalidated $\mathrm{FFQ}^{(21)}$.

In Brazil, data from family budget surveys carried out in all metropolitan areas in 1989 and 1996 suggested that the contributions derived from total fruits, fruit juices and vegetables to total energy intake were declining ${ }^{(22)}$. A more recent family budget survey conducted in 2002-3 estimated the individual acquisition of fruits and vegetables to be about $67 \mathrm{~g} / \mathrm{d}$ and $79 \mathrm{~g} / \mathrm{d}$, respectively ${ }^{(23)}$. These estimates are much lower than what has been recommended to reach nutritional needs for good health and the prevention of diet-related chronic diseases. It has been suggested that circulating antioxidant vitamins may be important in the natural history of cervical carcinogenesis in populations with lower intake levels of $\beta$-carotene ${ }^{(24)}$. In the present study, to report dietary food sources of serum carotenoids, retinol, $\alpha$ - and $\gamma$-tocopherols of low-income women, we investigated the determinants of these vitamins in the Brazilian Investigation into Nutrition and Cervical Cancer Prevention (BRINCA) study.

\section{Methods}

\section{Study population and design}

Participants were from the BRINCA study, a case-control hospital-based study designed to investigate the relationship among dietary factors, serum vitamin concentrations and cervical cancer in São Paulo city, São Paulo state, Brazil. The exclusion criteria were pregnancy, breast-feeding, hysterectomy, positive test for HIV, bleeding, mental disturbance, and radiotherapy or chemotherapy treatments. From March 2003 to May 2005, 1676 women completed the study protocol by filling out a questionnaire in three major public hospitals: the Brazilian Institute for Cancer Research, Hospital Leonor Mendes de Barros and Hospital Perola Byington. In the main study, we aimed to recruit prospectively newly diagnosed cases of cervical intraepithelial neoplasia (CIN) and invasive cancer. Eligible women were residents of São Paulo aged 18-65 years who had no prior hysterectomy, previous treatment for cervical neoplasia or cancer history. During the same period, control women were selected from among those attending screening in the same clinics where cases were diagnosed. Cases and controls were invited to participate in the study and interviewed before the colposcopy examination to minimize differential recall bias. The Institutional Review Board of the School of Public Health of the University of São Paulo and the Medical Ethical Committees of all participating hospitals approved the study protocol, and written informed consent was obtained from each participant.

For the present analysis we excluded the following participants because of concern that cancer treatment could have affected the associated factors under investigation: 148 with any diagnosis of invasive cancer, fifty-two who reported haemorrhage in the last 6 months, four HIV- positive, one with lupus, four younger $(<21$ years), one older ( $>65$ years), and thirty-one without any information in medical records. We also excluded eight participants considered outliers based on the reported dietary intake distribution $(<2929 \mathrm{~kJ} / \mathrm{d}(700 \mathrm{kcal} / \mathrm{d})$ or $>25105 \mathrm{~kJ} / \mathrm{d}$ $(6000 \mathrm{kcal} / \mathrm{d})$, corresponding to the $<2.5$ or $>97.5$ percentile, respectively). Of the 1427 eligible participants for the present study, 918 (64.3\%) provided blood samples.

\section{General and anthropometric information}

A general questionnaire was used to obtain data on medical and reproductive history, socio-economic characteristics, lifestyle, smoking and drinking habits. Selfreported ethnicity/race was defined in three categories used by the Instituto Brasileiro de Geografia e Estatística: white, black or mulatto (person with one black parent and other white parent). Physical activities were assessed by a structured physical activity questionnaire used in a previous study with good reproducibility (Spearman coefficient ranging from 0.51 to $0 \cdot 82)^{(25)}$. The questionnaire was developed using $24 \mathrm{~h}$ activity recalls to select the most frequent physical activities reported from people attending in a public health centre. Women were asked about frequency and time spent in practices of gym, physical fitness, cycling, sports, leisure-time physical activities, usual work, walking and household activities and care activities (child $<5$ years old or elderly). Time spent in each activity in hours per week was multiplied by energy expenditure, expressed in metabolic equivalents of task (MET), and then summed over all activities, to yield total MET $\times \mathrm{h} /$ week.

Anthropometry was performed with subjects wearing light clothes and no shoes using calibrated electronic scales (model MEA-07400; Measurement Specialities, Hampton, VA, USA). Height was measured with a tape measure fixed to a flat wall. Both measures were repeated, and the mean values were used to calculate BMI $\left(\mathrm{kg} / \mathrm{m}^{2}\right)$, which was then classified as normal $\left(\mathrm{BMI}<25 \mathrm{~kg} / \mathrm{m}^{2}\right.$ ), overweight (BMI $=$ $25 \cdot 00-29 \cdot 99 \mathrm{~kg} / \mathrm{m}^{2}$ ) or obese (BMI $\geq 30 \cdot 00 \mathrm{~kg} / \mathrm{m}^{2}$ ) according to the WHO guidelines ${ }^{(26)}$.

\section{Dietary data}

Food consumption was assessed using a previously validated FFQ adapted to the present study ${ }^{(25,27)}$. In summary, we conducted a validation study in a random sub-sample of ninety-six cases and controls from the BRINCA study (FFQ1), using three $24 \mathrm{~h}$ dietary recalls (DR) obtained during a year reported in a second FFQ (FFQ2). The energyadjusted intra-class correlations between FFQ1 and FFQ2 (one-year interval) ranged from 0•4-0.6 (B vitamins, Fe, Zn, $\mathrm{Mg}, \mathrm{P}$ and $\mathrm{Ca}$ ) to $0 \cdot 7$ (vitamin $\mathrm{A}$ and folate). The energyadjusted and de-attenuated Pearson correlations ( $r$ ) between FFQ and DR ranged from 0.3-0.4 (macronutrients and $\mathrm{B}$ vitamins) to $0 \cdot 5-0 \cdot 8$ (fibre, vitamin $\mathrm{A}, \mathrm{Ca}$, folate and P; MA Cardoso, EC Laguna, LY Tomita and V D'Almeida, unpublished results). 
Subjects were asked by trained nutritionists about the usual frequency of food consumption (seventy-six items) and portion sizes (small, medium, large and extra large) during the previous year. The nutrient composition of the diets was determined using the Dietsys software version $4 \cdot 01^{(28)}$. The nutrient database was based primarily on the US Department of Agriculture publications supplied by Dietsys and supplemented by the Brazilian Standard Food Composition Table only for the typical Brazilian recipe of feijoada (black beans cooked with pork and beef) ${ }^{(29)}$. The subjects were also questioned about the use of vitamin supplements (commercial name or brand, frequency and duration) within the past year. For the present study, we investigated macronutrients, vitamins, minerals and five food groups: (i) dark green and deep yellow vegetables and fruits (green salad, kale, broccoli, spinach, pumpkin, carrot, sweet potatoes, papaya and mango); (ii) total fruits and juices; (iii) citrus fruits and juices only; (iv) total vegetables; and (v) total F\&V.

\section{Blood collection and laboratory analyses}

Fasting venous blood samples, protected from light, were collected into anticoagulant-free tubes, centrifuged at $1300 \mathrm{rpm}$ for $13 \mathrm{~min}$ within the first hour of collection and stored at $-70^{\circ} \mathrm{C}$ until analysis. Unfortunately, we were not able to separate $\beta$-, $\alpha$ - and $\gamma$-carotene when the analysis was run. As $\beta$-carotene is considered the most prevalent carotenoid in plasma, in the present study serum samples were analysed for total carotene including $\beta$-, $\alpha$ - and $\gamma$ carotene, lycopene, $\alpha$ - and $\gamma$-tocopherols and retinol by reversed-phase HPLC (HP-1100 system; Hewlett Packard, Palo Alto, CA, USA) ${ }^{(30)}$. As previously described ${ }^{(31)}$, lipid extracts from serum samples were prepared with methanol/hexane. The pellet obtained after final solvent evaporation was dissolved in $0.4 \mathrm{ml}$ methanol-ethanol (1:1, $\mathrm{v} / \mathrm{v})$ for injection into the chromatograph. Aliquots of $20 \mu \mathrm{l}$ were injected on to a $3.9 \mathrm{~mm} \times 150 \mathrm{~mm}$ C8 Nova-Pak column, under isocratic mobile phase delivery $(20 \mathrm{~mm}-$ $\mathrm{LiClO}_{4}$ in methanol-water $\left.(98: 2, \mathrm{v} / \mathrm{v}), 0.7 \mathrm{ml} / \mathrm{min}\right)$. An electrochemical detector (Bioanalytical Systems, Inc., West Lafayette, IN, USA) was used, with an oxidation potential of $0.6 \mathrm{~V}$. The observed wavelengths and retention times were, respectively, $325 \mathrm{~nm}$ and $2 \mathrm{~min} 0 \mathrm{~s}( \pm 0 \cdot 2 \mathrm{~s}$ ) for retinol, $280 \mathrm{~nm}$ and $3 \mathrm{~min} 33 \mathrm{~s}( \pm 0 \cdot 2 \mathrm{~s})$ for $\gamma$-tocopherol, $280 \mathrm{~nm}$ and $3 \mathrm{~min} 56 \mathrm{~s}( \pm 0 \cdot 2 \mathrm{~s})$ for $\alpha$-tocopherol, $450 \mathrm{~nm}$ and $5 \mathrm{~min}$ $54 \mathrm{~s}( \pm 0 \cdot 2 \mathrm{~s})$ for lycopene, $450 \mathrm{~nm}$ and $7 \mathrm{~min} 34 \mathrm{~s}( \pm 0 \cdot 2 \mathrm{~s})$ for $\beta$-carotene, in a single run (total run of $10 \mathrm{~min}$ ).

The peaks for carotenoids that were under the quantification limits were set to zero (five samples for total carotene, one for lycopene and two for $\boldsymbol{\gamma}$ - tocopherol; detectable levels of total carotene, lycopene and $\gamma$ - tocopherol were respectively $0 \cdot 5,0 \cdot 1$ and $0 \cdot 2 \mu \mathrm{mol} / \mathrm{l}$ ). Serum total cholesterol was measured enzymatically using an automatic device (ADVIA 1650; Bayer, East Walpole, MA, USA). All samples were analysed within 6 months of collection. The laboratory assayed internal and external blinded quality control specimens in every run. From the control specimens, the accuracy and inter-assay $\mathrm{CV}$ for all of these analytes were within $8 \%$.

\section{Statistical methods}

Dietary intakes and biomarker concentrations were logtransformed before analysis. The dietary nutrient intakes were adjusted for total energy intake using the residual $\operatorname{method}^{(32)}$. Serum vitamin concentrations did not differ according to supplement use owing to the small number of current users ( $n 13,1.4 \%)$. Monthly per capita income was converted from Reals (Brazilian currency) to US dollars using the mean monthly exchange conversion rate. Cervical cytology was classified in accordance with WHO criteria.

Pearson correlation coefficients were used to assess potential correlations between total carotene, lycopene, $\alpha$ - and $\gamma$-tocopherols and retinol concentrations and the continuous variables: age (years), education (years of schooling), BMI, fasting time (h), total serum cholesterol concentration and dietary intake. Tests for linear trend were calculated by assigning a median value for each serum micronutrient and modelling this as a continuous variable across categories of race/ethnicity, income, smoking status, oral contraceptive use, alcohol intake, season of blood collection and cervical cytological classification. Pearson correlation coefficients were also used in assessing correlations between the dietary factors and serum micronutrients. These correlations were further investigated using multiple linear regression models, with dietary intake as the independent variable and serum carotene, tocopherols and retinol as the dependent variable. The regression coefficients $\left(\beta_{1}\right)$ and the coefficients of determination (adjusted $R^{2}$ ) were estimated using multiple separate models for each serum vitamin, adjusting for potential confounding variables selected in a stepwise forward procedure based on $P<0.05$ for estimated $\beta_{1}$ and change in adjusted $R^{2}$. Estimated food groups and nutrient intakes were included in linear multiple regression models in the last step to determine their independent effect on serum micronutrient levels. Calculation of partial $R^{2}$ was used to assess the degree of variability each dietary variable contributed to serum micronutrients, expressed as a percentage. Stratified analyses by smoking status (non-smoker $v$. current smoker) were conducted to test whether a significant interaction existed between smoking, food group intakes and serum total carotene levels. Adjusted mean intake of food groups and serum total carotene were compared in smokers $v$. non-smokers using ANOVA. The independent effect of smoking on serum total carotene concentrations was estimated and assessed for linear trend across quartiles of food intake after adjusting for confounding variables. None of the variables were collinear. Statistical significance was estimated using $P<0 \cdot 05$. All analyses were performed using the STATA statistical software package version $9 \cdot 0$ (Statacorp, College Station, TX, USA). 


\section{Results}

The distribution of participants across hospitals was 511 (55.7\%) from Brazilian Institute for Cancer Research, 331 (36.0\%) from Perola Byington and seventy-six (8.3\%) from Leonor Mendes de Barros. Most of the participants were housewives or unemployed, 420 (45.8\%), with a median monthly income of $\$$ US $63 \cdot 5$. A high proportion of overweight and obesity for a developing country was observed: $278(30 \cdot 3 \%)$ and $147(16 \cdot 0 \%)$, respectively. Other general characteristics, dietary intake and the biomarker concentrations are presented in Table 1.

Serum concentrations of carotenoids, retinol and tocopherols were positively correlated with serum total cholesterol and age $(P<0 \cdot 005)$. The strongest correlation coefficients were observed between serum total carotene and BMI $(r=0 \cdot 60, P=0 \cdot 02)$. Serum total carotene levels were strongly correlated with serum lycopene $(r=0 \cdot 42$, $P<0 \cdot 001)$, serum $\alpha$-tocopherol $(r=0.45, P<0.001)$ and serum $\gamma$-tocopherol $(r=0.34, \quad P<0 \cdot 001)$. The medians and interquartile ranges of serum vitamins according to the main characteristics of the participants are shown in Table 2. Alcohol consumption was not significantly different across quartiles of serum vitamin levels. The proportion of current and former smokers was high (49.6\%), with statistically significant differences in serum total carotene concentration according to smoking status $(P=0 \cdot 005)$.
Serum total carotene concentrations were positively correlated with intakes of dark green and deep yellow vegetables and fruits $(r=0 \cdot 27)$, total fruits and juices $(r=0 \cdot 18)$, carrots $(r=0 \cdot 18)$, total $\mathrm{F} \& \mathrm{~V}(r=0 \cdot 17)$ and citrus fruits and juices only $(r=0 \cdot 12)$. They were negatively correlated with sweets and snacks $(r=-0 \cdot 12$; $P<0.001$ for all). Among energy-adjusted nutrients, the highest Pearson correlation coefficients were observed between serum total carotene concentrations and dietary intakes of pro-vitamin A carotenoids $(r=0 \cdot 24)$, vitamin A (IU; $r=0 \cdot 23), \beta$-carotene $(r=0 \cdot 23)$ and $\alpha$-carotene $(r=0 \cdot 21 ; P<0 \cdot 001$ for all).

The results of multiple linear regression analyses between dietary factors and serum total carotene levels are summarized in Table 3 . The intake of vegetables and fruits, mainly dark green and deep yellow ones, was the strongest dietary predictor of serum total carotene concentration in our study population, after adjusting for confounding variables. Ham and sausage consumption was a negative determinant of serum total carotene levels after adjusting for confounding variables. For serum concentrations of tocopherols, only dietary pro-vitamin A carotenoids and vitamin $\mathrm{C}$ were positively associated with $\alpha$-tocopherol levels (partial $R^{2}=0.5 \%$ and $0.6 \%$, respectively, adjusted for age, serum total cholesterol, season of blood collection and BMI); while the intake of ham and sausages (partial $R^{2}=0.5 \%$ ) and sweets (partial

Table 1 Characteristics of the study population: low-income women $(n 918)$ aged 21-65 years participating in the Brazilian Investigation into Nutrition and Cervical Cancer Prevention (BRINCA) study

\begin{tabular}{|c|c|c|}
\hline Variable & Median & IQR \\
\hline Age (years) & $38 \cdot 0$ & $29 \cdot 8,47 \cdot 0$ \\
\hline Schooling (years) & $7 \cdot 0$ & $4 \cdot 0,11 \cdot 0$ \\
\hline Monthly per capita income (\$US) & $63 \cdot 5$ & $35 \cdot 0,113 \cdot 0$ \\
\hline BMI $\left(\mathrm{kg} / \mathrm{m}^{2}\right)$ & $24 \cdot 7$ & $22 \cdot 0,28 \cdot 2$ \\
\hline Total physical activity (MET $\times \mathrm{h} /$ week) & $137 \cdot 7$ & $83 \cdot 5,205 \cdot 0$ \\
\hline \multicolumn{3}{|l|}{ Biomarkers } \\
\hline Total carotene $(\mu \mathrm{mol} / \mathrm{l})$ & 0.66 & $0 \cdot 37,1 \cdot 17$ \\
\hline Lycopene $(\mu \mathrm{mol} / \mathrm{l})$ & 0.90 & $0.50,1.46$ \\
\hline Retinol $(\mu \mathrm{mol} / \mathrm{l})$ & $1 \cdot 73$ & $1 \cdot 30,2 \cdot 38$ \\
\hline$\alpha$-Tocopherol $(\mu \mathrm{mol} / \mathrm{l})$ & $14 \cdot 80$ & $10 \cdot 90,19 \cdot 72$ \\
\hline$\gamma$-Tocopherol $(\mu \mathrm{mol} / \mathrm{l})$ & $1 \cdot 80$ & $1 \cdot 30,2 \cdot 30$ \\
\hline Total cholesterol (mg/dl) & $191 \cdot 0$ & $167 \cdot 0,222 \cdot 0$ \\
\hline \multicolumn{3}{|l|}{ Daily nutrient, food group and alcohol intakes } \\
\hline Total energy $(\mathrm{kJ})$ & $8657 \cdot 9$ & $7070 \cdot 7,10925 \cdot 0$ \\
\hline Protein (\% of energy) & $14 \cdot 7$ & $12 \cdot 6,16 \cdot 8$ \\
\hline Carbohydrate (\% of energy) & $52 \cdot 5$ & $47 \cdot 8,57 \cdot 8$ \\
\hline Fat (\% of energy) & $31 \cdot 9$ & $27 \cdot 7,35 \cdot 4$ \\
\hline Total fibre $(\mathrm{g})$ & $14 \cdot 1$ & $10 \cdot 4,18 \cdot 4$ \\
\hline Folate $(\mu \mathrm{g})$ & $185 \cdot 7$ & $137 \cdot 9,244 \cdot 9$ \\
\hline Vitamin C (mg) & $118 \cdot 7$ & $74 \cdot 3,190 \cdot 8$ \\
\hline Vitamin E (mg) & $7 \cdot 2$ & $5 \cdot 9,9 \cdot 0$ \\
\hline Pro-vitamin A carotenoids (mg) & $2139 \cdot 0$ & $1132 \cdot 5,3501 \cdot 5$ \\
\hline$\alpha$-Carotene (mg) & $140 \cdot 8$ & $59 \cdot 0,280 \cdot 7$ \\
\hline$\beta$-Carotene (mg) & $1748 \cdot 2$ & $933 \cdot 1,2940 \cdot 8$ \\
\hline Lycopene (mg) & $976 \cdot 5$ & $552 \cdot 2,1621 \cdot 3$ \\
\hline Vitamin A (IU) & 8763 & 8313,9214 \\
\hline Total fruits and juices (g/d) & $148 \cdot 1$ & $63 \cdot 3,286 \cdot 8$ \\
\hline Dark green \& deep yellow vegetables \& fruits $(\mathrm{g} / \mathrm{d})$ & $25 \cdot 0$ & $9 \cdot 6,51 \cdot 5$ \\
\hline Total vegetables $(\mathrm{g} / \mathrm{d})$ & $98 \cdot 9$ & $61 \cdot 6,149 \cdot 6$ \\
\hline Alcohol (g/d) & $0 \cdot 2$ & $0,24 \cdot 7$ \\
\hline
\end{tabular}

IQR, interquartile range. 


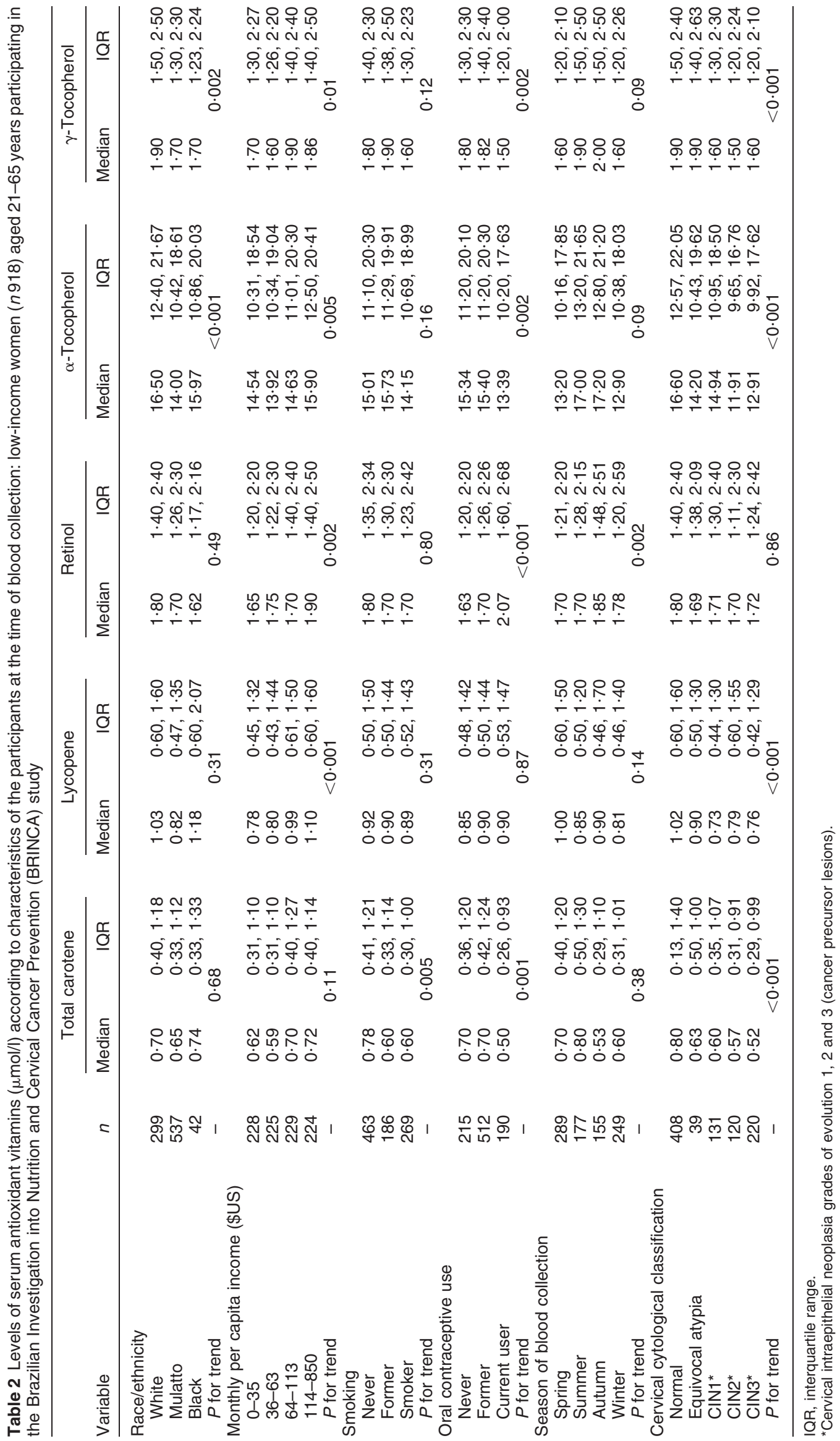


Table 3 Dietary predictors of serum concentrations of total carotene: low-income women $(n$ 918) aged 21-65 years participating in the Brazilian Investigation into Nutrition and Cervical Cancer Prevention (BRINCA) study

\begin{tabular}{|c|c|c|c|}
\hline \multirow[b]{2}{*}{ Dietary intake } & \multicolumn{3}{|c|}{ Serum total carotene ${ }^{*}$} \\
\hline & $\beta_{1}$ & $95 \% \mathrm{Cl}$ & Partial $R^{2}(\%)$ \\
\hline \multicolumn{4}{|l|}{ Food groups } \\
\hline Dark green \& deep yellow vegetables \& fruit $(\mathrm{g} / \mathrm{d})$ & $0.059 \ddagger$ & $0.041,0.078$ & $4 \cdot 8$ \\
\hline Total fruits and juices $(\mathrm{g} / \mathrm{d})$ & $0.034 \ddagger$ & $0.017,0.052$ & $1 \cdot 8$ \\
\hline Total fruits and vegetables $(\mathrm{g} / \mathrm{d})$ & $0.054 \ddagger$ & $0.027,0.082$ & $1 \cdot 8$ \\
\hline Carrots $(\mathrm{g} / \mathrm{d})$ & $0.029 \ddagger$ & $0.012,0.045$ & $1 \cdot 4$ \\
\hline Total vegetables $(\mathrm{g} / \mathrm{d})$ & $0.050 \ddagger$ & $0.020,0.080$ & $1 \cdot 3$ \\
\hline Fish and seafood $(\mathrm{g} / \mathrm{d})$ & $0.027 \ddagger$ & $0.011,0.044$ & $1 \cdot 3$ \\
\hline Ham and sausage $(\mathrm{g} / \mathrm{d})$ & $-0.027 \S$ & $-0.046,-0.008$ & 0.9 \\
\hline Tomato and watermelon $(\mathrm{g} / \mathrm{d})$ & $0.027 \|$ & $0.007,0.046$ & 0.9 \\
\hline Citrus fruits and juices only $(\mathrm{g} / \mathrm{d})$ & $0.018 \|$ & $0.004,0.032$ & $0 \cdot 8$ \\
\hline \multicolumn{4}{|l|}{ Energy-adjusted nutrientst } \\
\hline Vitamin A (IU) & $0 \cdot 104 \ddagger$ & $0.071,0.136$ & $4 \cdot 5$ \\
\hline Pro-vitamin A carotenoids (mg) & $0.077 \ddagger$ & $0.051,0.103$ & $3 \cdot 9$ \\
\hline$\beta$-Carotene (mg) & $0.074 \ddagger$ & $0.048,0.099$ & $3 \cdot 6$ \\
\hline$\alpha$-Carotene (mg) & $0.047 \ddagger$ & $0.029,0.065$ & $3 \cdot 2$ \\
\hline Vitamin $B_{12}(\mathrm{mg})$ & $0.066 \ddagger$ & $0.037,0.095$ & $2 \cdot 4$ \\
\hline Niacin $(\mathrm{mg})$ & $0 \cdot 153 \ddagger$ & $0.065,0.240$ & $1 \cdot 4$ \\
\hline$\beta$-Cryptoxanthin (mg) & $0.031 \ddagger$ & $0.013,0.050$ & $1 \cdot 3$ \\
\hline Vitamin C (mg) & $0.052 \ddagger$ & $0.020,0.084$ & $1 \cdot 2$ \\
\hline Vitamin $\mathrm{B}_{6}(\mathrm{mg})$ & $0.212 \ddagger$ & $0.083,0.341$ & $1 \cdot 2$ \\
\hline Folate $(\mu \mathrm{g})$ & $0 \cdot 102 \S$ & $0.037,0.167$ & $1 \cdot 1$ \\
\hline Fat $(\mathrm{g})$ & $-0.155 \S$ & $-0.268,-0.042$ & 0.9 \\
\hline $\mathrm{K}(\mathrm{mg})$ & $0 \cdot 109 \|$ & $0.023,0.194$ & $0 \cdot 7$ \\
\hline $\mathrm{Fe}(\mathrm{mg})$ & $0 \cdot 150 \|$ & $0.031,0.272$ & $0 \cdot 7$ \\
\hline
\end{tabular}

*Adjusted for age (years), serum total cholesterol (continuous), hospital, cervical cytological classification, BMI (continuous) and smoking status (never, former, current).

tEnergy adjustment by the residual method.

$\ddagger P \leq 0.001$.

$\S P \leq 0.005$.

$\| P<0.05$.

$\left.R^{2}=0 \cdot 5 \%\right)$ was inversely correlated with $\gamma$-tocopherol levels (adjusted for the same covariates as for $\alpha$-tocopherol plus cervical cytological classification and race/ ethnicity). No dietary predictors were observed for serum lycopene and retinol in our study population. The strongest positive predictors of serum concentrations of lycopene were income, hospital, cervical lesion, alcohol consumption and serum total cholesterol (adjusted $R^{2}=0.078$ ); while those of serum retinol levels were income, alcohol consumption, serum total cholesterol and season of blood collection (adjusted $R^{2}=0 \cdot 052$ ).

As expected, the highest median dietary intakes of total fruits and juices and dark green and deep yellow vegetables and fruits were observed in non-smokers compared with smokers: 161.40 and $123.0 \mathrm{~g} / \mathrm{d}$ for total fruits and juices, and $26 \cdot 4$ and $21 \cdot 1 \mathrm{~g} / \mathrm{d}$ for dark green and deep yellow vegetables and fruits, respectively. Figure 1 illustrates the association between adjusted mean serum total carotene concentrations and intake quartiles of dark green and deep yellow vegetables and fruits and total fruits and juices according to smoking status, adjusted for confounding variables. A significant trend was found, showing increasing serum total carotene values with increasing quartiles of dietary intake of both food groups in non-smokers $(P$ for trend $<0 \cdot 001)$ and smokers ( $P$ for trend $<0 \cdot 001$ ). Median (interquartile range) serum total carotene concentration $(\mu \mathrm{mol} / \mathrm{l})$ adjusted for confounding variables and intake of total fruits and juices was $0.45(0.38,0.52)$ and $0.51(0.44,0.59)$ for smokers and non-smokers, respectively $(P<0 \cdot 001)$; and adjusted for dark green and deep yellow vegetables and fruits was $0.48(0.39,0.55)$ and $0.53(0.45,0.62)$ for smokers and non-smokers, respectively $(P<0 \cdot 001)$.

\section{Discussion}

In the present study, we found that dark green and deep yellow vegetables and fruits, total fruits and juices, citrus fruits and juices only and carrots were independent predictors of serum total carotene levels in low-income Brazilian women. The median F\&V intake (about $250 \mathrm{~g} / \mathrm{d}$ ) was lower than the WHO recommendation of $400 \mathrm{~g} / \mathrm{d}$ for this food group ${ }^{(2)}$ and the intake of wholegrain cereals was unusual. In the present population, serum retinol levels were in the normal range as established by the Food and Nutrition Board criteria $^{(33)}$, and serum concentrations of total carotene and lycopene were higher than the values observed in the Third National Health and Nutrition Examination Survey (NHANES III) among nonsmoking women ${ }^{(34)}$. However, lower intakes of F\&V similar to the levels in our study population were found in a study conducted among adolescents in Costa Rica, where daily consumption of one portion of fruit (112g) 
(a)

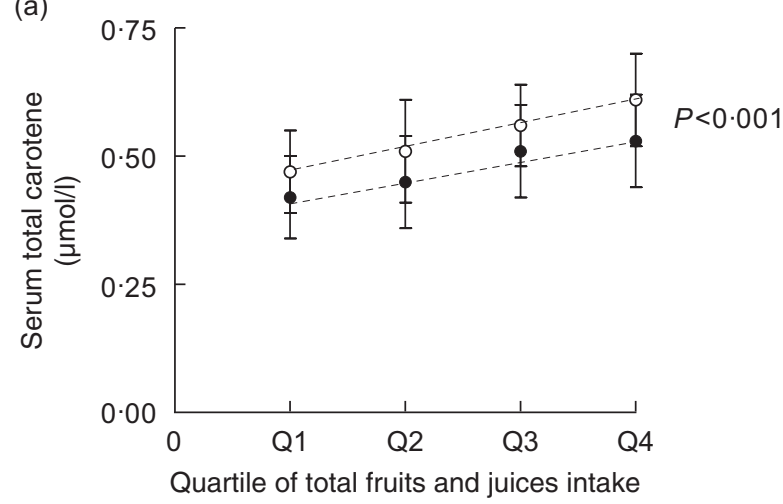

(b)

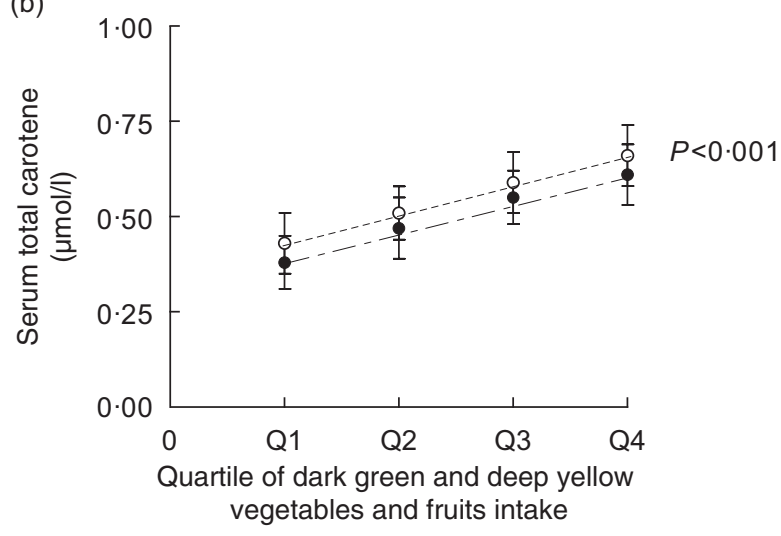

Fig. 1 Adjusted mean $(95 \% \mathrm{Cl})$ serum total carotene level by intake quartile of total fruits and juices (a) and dark green and deep yellow vegetables and fruits (b) according to smoking status $(O$, non-smokers; $\bullet$, smokers) among low-income women ( $n$ 918) aged 21-65 years participating in the Brazilian Investigation into Nutrition and Cervical Cancer Prevention (BRINCA) study. Mean serum concentrations of total carotene were adjusted for age, serum cholesterol, BMI, hospital and cervical cytological classification. Range of dietary intakes (g/d), Q1 to Q4: 0-63.2, 63.3-147.8, 147.9-286.8 and $286 \cdot 9-490 \cdot 8$ for total fruits and juices; $0-9 \cdot 5,9 \cdot 6-24 \cdot 9$, $25 \cdot 0-51 \cdot 5$ and $51 \cdot 6-362 \cdot 3$ for dark green and deep yellow vegetables and fruit

was reported by $\sim 84 \%$ and that of green vegetables (23g) by $\sim 34 \%$ of the participants ${ }^{(20)}$.

In our study, differences in serum total cholesterol, age, hospital attended, cervical cytological classification, BMI, smoking status and intake of dark green and deep yellow vegetables and fruits explained $14 \cdot 4 \%$ of the variation of serum total carotene concentrations. Previous studies explained $10 \cdot 7 \%$ to $39 \cdot 4 \%$ in multivariate models that included age, gender, smoking, alcohol intake, serum cholesterol and/or TAG, total energy intake, and vegetable and fruit or $\beta$-carotene intake $e^{(4,7,13,14,16,35)}$. Smoking has been negatively correlated with circulating $\beta$-carotene levels ${ }^{(4,7,12-13,17,36,37)}$, with reported lower dietary intake of $\beta$-carotene in smokers compared with nonsmokers ${ }^{(12,34,35,38-40)}$. In our study, there was no evidence of the above interaction, and a similar trend of increasing serum total carotene concentrations with increasing intakes of dietary food sources of carotenes was noted in both smoking and non-smoking participants after adjusting for confounding variables. However, a slight decrease in serum total carotene concentrations was observed among smokers compared with non-smokers at the same dietary intake levels probably due to destruction of carotenes by highly oxidative tobacco smoke ${ }^{(41)}$.

Other variables identified in previous studies, such as oral contraceptive (OC) use, were not significant in multiple linear models in our study. It has been reported that OC users have lower levels of serum $\beta$-carotene $^{(42,43)}$. In a representative sample of US women, OC users had lower dietary intake of carotenoids, were more likely to smoke and drink, were married and highly educated compared with non-users of OC, after adjusting for confounding variables ${ }^{(40)}$. One explanation suggested for the lower levels of $\beta$-carotene among OC users is related to the decrease in LDL levels used to carry $\beta$-carotene in plasma. The negative correlation between alcohol consumption and blood $\beta$-carotene concentrations has been explained by the oxidative stress mechanisms among regular drinkers ${ }^{(4,12-14,44,45)}$.

Similar seasonal variation in serum concentrations of total carotene and tocopherols found in the present study was reported previously ${ }^{(4,46)}$. The positive correlation between temperature and plasma carotene was explained by the variation in dietary sources according to season, with light and heat contributing to increase the carotenoid contents of specific $F \& V^{(46)}$. In the south-eastern part of Brazil, important differences in food availability, environmental temperature and humidity are expected at least between summer and winter. Higher consumption of energy-dense foods in winter could be responsible for the increased concentrations of $\alpha$ - and $\gamma$-tocopherols, which in turn was strongly correlated with serum total cholesterol.

Few earlier studies have assessed the correlation between serum levels of micronutrients and dietary intakes in multiple models. In Brazil, one previous study with 100 women in the sub-cohort sample living in São Paulo city mentioned strong crude correlations $(r>0 \cdot 40$; data not shown) between the consumption of carrots and serum $\alpha$-carotene and $\beta$-carotene levels, and between citrus fruit intake and serum lycopene levels ${ }^{(47)}$. However, few studies have correlated dietary intakes and blood carotene levels after adjusting for confounding variables. In the New York Women's Health Study involving 228 women $^{(16)}$ and in the European Prospective Investigation into Cancer and Nutrition with 2974 participants $^{(4)}$, total vegetable intake and tomato and its products accounted for $7 \%$ and $14 \%$ of blood lycopene levels, respectively, after adjusting for confounding variables. In a sub-sample of NHANES III ( $n$ 3413), the frequency of consumption of pizza, pasta and tomato was a significant determinant of serum lycopene levels ${ }^{(6)}$; and in Massachusetts Hispanic elders, total carotenoid intake was a predictor of blood lycopene levels ${ }^{(7)}$. Other 
studies did not find any correlation, possibly due to small sample size $(n<400)$, low intakes or poor accuracy in estimates of the main food sources of lycopene ${ }^{(10,11,14,17)}$.

Similarly to our study, determinants of serum retinol such as income, alcohol consumption, serum total cholesterol concentration and season of blood collection were found in other studies ${ }^{(13)}$. Determinants of blood levels of $\alpha$-tocopherol reported previously were age, education, body weight or BMI, blood cholesterol and/or TAG, cigarette use, total energy, alcohol and fat intake $^{(9,12,36)}$. Only two studies in adults and children found a significant correlation between dietary intake of vitamin $\mathrm{E}$ and plasma $\alpha$-tocopherol levels ${ }^{(34,48)}$. The lack of significant dietary predictors for circulating tocopherols after adjusting for confounders may be related to the inaccuracy of the FFQ to capture total intakes of vegetable oil, its major dietary source. In our study, we included additional items about type and frequency of vegetable oil use, but it may not have been sufficient to better estimate vitamin $\mathrm{E}$ dietary sources.

It is possible that the estimated $\beta_{1}$ in our cross-sectional study was lower than the true slope since we collected only one blood sample and blood micronutrient levels vary on a daily basis. This daily variability can attenuate the relationship between the dietary exposure and the blood levels. In a previous study, Block et al. ${ }^{(49)}$ estimated that two or three independent blood samples for $\beta$-carotene and two to five samples for lycopene are necessary to minimize the attenuation effect of measures, which is difficult to perform in large population studies. These authors also recommended the use of blood samples collected in 2- to 4-week intervals for non-smokers or passive smokers with dietary intakes of F\&V less than 4 servings/d. A single measurement of plasma carotenoids could introduce non-differential misclassification, which will bias the association towards the null ${ }^{(50)}$. This may also explain the relatively low correlation between dietary carotenoids and plasma carotenoids in the present study.

To our knowledge, the present study is the first one to look for determinants of serum total carotene levels in a Brazilian population. Our findings were similar to those of previous studies conducted in participants with higher educational and income levels in developed countries. Since carotenoids lack a regulatory homeostatic mechanism, their serum level has been considered the best biomarker for F\&V consumption ${ }^{(33)}$.Thus, measures of serum carotene concentrations should be included to complement FFQ validation studies in populations with low $F \& V$ intake.

\section{Acknowledgements}

Sources of funding: Funding was provided by the Fundação de Amparo à Pesquisa do Estado de São Paulo, Brazil (FAPESP; 03/03013-4) and the Conselho Nacional de Desenvolvimento Científico e Tecnológico, Brazil
(CNPq; 473043/03-3, 300167/97-0 and 506486/2003-6). L.Y.T. received PhD scholarships from FAPESP (02/111840) and Coordenação de Aperfeiçoamento de Pessoal de Nível Superior (CAPES; BEX3775/05-4). Conflict of interest declaration: The authors have no conflicts of interest. Authorship responsibilities: L.Y.T. collected the data and performed the statistical analysis. L.C.A. and C.R.-M. were involved in the field work and data entry. V.D. supervised the laboratory measurements. M.A.C., the overall coordinator, supervised all aspects of the study and, together with L.Y.T., wrote the manuscript. All authors participated in the interpretation of the results and the preparation of the final version of the manuscript. Acknowledgements: We thank the physicians and administrators at the Instituto Brasileiro de Controle do Câncer, Hospital Leonor Mendes de Barros and Hospital Perola Byington for their support of this study. We are also grateful to all participants and to our field research work team: Lucila Pereira, Adelisa Isabel da Silva and Carlos Eduardo Teixeira Fernandez.

\section{References}

1. World Cancer Research Fund/American Institute for Cancer Research (2007) Food, Nutrition, Physical Activity, and the Prevention of Cancer: A Global Perspective. Washington, DC: AICR.

2. World Health Organization (2003) Diet, Nutrition and the Prevention of Chronic Diseases. WHO Technical Report Series no. 916. Geneva: WHO.

3. Olson JA (1999) Bioavailability of carotenoids. Arch Latinoam Nutr 49, Suppl. 1, S21-S25.

4. Al-Delaimy WK, Slimani N, Ferrari P et al. (2005) Plasma carotenoids as biomarkers of intake of fruits and vegetables: individual-level correlations in the European Prospective Investigation into Cancer and Nutrition (EPIC). Eur J Clin Nutr 59, 1387-1396.

5. Coyne T, Ibiebele TI, McNaughton S, Rutishauser IHE, O'Dea K, Hodge AM, McClintock C, Findlay MG \& Lee A (2005) Evaluation of brief dietary questionnaire to estimate vegetable and fruit consumption - using serum carotenoids and red-cell folate. Public Health Nutr 8, 298-308.

6. Ganji V \& Kafai MR (2005) Population determinants of serum lycopene concentrations in the United States: data from the Third National Health and Nutrition Examination Survey, 1988-1994. J Nutr 135, 567-572.

7. Bermudez OI, Ribaya-Mercado JD, Talegawkar SA \& Tucker K (2005) Hispanic and non-Hispanic white elders from Massachusetts have different patterns of carotenoid intake and plasma concentrations. J Nutr 135, 1496-1502.

8. Darmon N \& Drewnowski A (2008) Does social class predict diet quality? Am J Clin Nutr 87, 1107-1117.

9. Block $G$, Norkus E, Hudes $M$, Mandel $S$ \& Heizisouer $K$ (2001) Which plasma antioxidants are most related to fruit and vegetable consumption? Am J Epidemiol 154, 1113-1118.

10. Bogers RP, van Assema P, Kester ADM, Westyerterp KR \& Dagnelle PC (2004) Reproducibility, validity, and responsiveness to change of a short questionnaire for measuring fruit and vegetable intake. Am J Epidemiol 159, 900-909.

11. Andersen LF, Veierod MB, Johansson L, Sakhi A, Solvoll K \& Drevon CA (2005) Evaluation of three dietary assessment methods and serum biomarkers as measures of fruit and 
vegetable intake, using the methods of triads. Br J Nutr $\mathbf{9 3}$ 519-527.

12. Galan P, Viteri FE, Bertrais $S$ et al. (2005) Serum concentrations of $\beta$-carotene, vitamin $\mathrm{C}$ and $\mathrm{E}$, zinc and selenium are influenced by sex, age, diet, smoking status, alcohol consumption and corpulence in a general French adult population. Eur J Clin Nutr 59, 1181-1190.

13. Faure H, Preziosi P, Roussel AM, Betrais S, Galan P, Hercberg S \& Favier A (2006) Factors influencing blood concentration of retinol, $\alpha$-tocopherol, vitamin $C$, and $\beta$ carotene in the French participants of the SU.VI.MAX trial. Eur J Clin Nutr 60, 706-717.

14. Campbell DR, Gross MD, Martini MFC, Grandits GA, Slavin JL \& Potter JD (1994) Plasma carotenoids as biomarkers of vegetable and fruit intake. Cancer Epidemiol Biomarkers Prev 3, 493-500.

15. Martini MC, Campbell DR, Gross MD, Grandits GA, Potter JD \& Slabin JL (1995) Plasma carotenoids as biomarkers of vegetable intake: the University of Minnesota cancer prevention research unit feeding studies. Cancer Epidemiol Biomarkers Prev 4, 491-496.

16. Van Kappel AN, Steghens JP, Zeleniuch-Jacquotte A, Chajès V, Toniolo P \& Riboli E (2000) Serum carotenoids as biomarkers of fruit and vegetable consumption in the New York Women's Health Study. Public Health Nutr 4, 829-835.

17. Resnicow K, Odom E, Wang T, Dudley WN, Mitchell D, Vaughan R, Jackson A \& Baranowski T (2000) Validation of three food frequency questionnaires and 24-hour recalls with serum carotenoid levels in a sample of AfricanAmerican adults. Am J Epidemiol 152, 1072-1080.

18. Tangney CC, Bienias JL, Evans DA \& Morris MC (2004) Reasonable estimates of serum vitamin E, vitamin $\mathrm{C}$, and $\beta$-cryptoxanthin are obtained with a food frequency questionnaire in older black and white adults. J Nutr 134, 927-934.

19. Romieu I, Parra S, Hernández JF, Madrigal H, Willett W \& Hernández M (1999) Questionnaire assessment of antioxidants and retinol intake in Mexican women. Arch Med Res 30, 224-239.

20. Irwig MS, El-Sohemy AE, Baylin A, Rifai N \& Campos H (2002) Frequent intake of tropical fruits that are rich in $\beta$-cryptoxanthin is associated with higher plasma $\beta$-cryptoxanthin concentrations in Costa Rican adolescents. J Nutr 132, 1361-3167.

21. Matos CM, Schweigert F, Sintes GS, Rodríguez GP, Hurtienne A, Reyes D \& Alonso Jiménez E (2002) Carotenoides séricos y su relación con la dieta en un grupo de adultos cubanos. Rev Cubana Aliment Nutr 16, 105-113.

22. Monteiro CA, Mondini L \& Costa RBL (2000) Secular changes in dietary patterns in the metropolitan areas of Brazil (1988-1996). Rev Saude Publica 34, 251-258.

23. Instituto Brasileiro de Geografia e Estatística (2004) Pesquisa de Orçamentos Familiares 2002/2003: Análise da disponibilidade domiciliar de alimentos e do estado nutricional no Brasil. Rio de Janeiro: IBGE; available at http://www.ibge. gov.br/home/estatistica/populacao/condicaodevida/pof/ 2002analise/default.shtm

24. Giuliano AR, Papenfuss M, Nour M, Canfield LM, Schneider A \& Hatch K (1997) Antioxidant nutrients: associations with persistent human papillomavirus infection. Cancer Epidemiol Biomarkers Prev 6, 917-923.

25. Sartorelli DS, Sciarra EC, Franco LJ \& Cardoso MA (2005) Beneficial effects of short-term nutritional counselling at the primary health-care level among Brazilian adults. Public Health Nutr 8, 820-825.

26. World Health Organization (2000) Obesity: Preventing and Managing the Global Epidemic. WHO Technical Report Series no. 894. Geneva: WHO.
27. Cardoso MA, Kida AA, Tomita LY \& Stocco PR (2001) Reproducibility and relative validity of a food frequency questionnaire among women of Japanese ancestry living in Brazil. Nutr Res 21, 725-733.

28. Block G, Coyle LM, Harmen AM \& Scoppa SM (1994) Revision of dietary analysis software for the health habits and history questionnaire. Am J Epidemiol 139, 1190-1196.

29. Instituto Brasileiro de Geografia e Estatística (1996) Estudo Nacional de Despesa Familiar Tabela de Composição de Alimentos, 4th ed. Rio de Janeiro: IBGE.

30. Vuilleumier JP, Keller HE, Gysel D \& Hunziker F (1983) Clinical chemical methods for the routine assessment of the vitamins status in human populations. Int J Vitamin Nutr Res 53, 265-272.

31. Gomes LF, Alves AF, Sevanian A, Peres CA, Cendoroglo MS, Mello-Almada C, Quirino LM, Ramos LR \& Junqueira VBC (2004) Role of $\beta 2$-glycoprotein I, LDL-, and antioxidant levels in hypercholesterolemic elderly subjects. Antioxid Redox Signal 6, 237-244.

32. Willett WC, Howe GR \& Kushi LH (1997) Adjustment for total energy intake in epidemiologic studies. Am J Clin Nutr 65, Suppl. 4, S1220-S1228.

33. Food and Nutrition Board, Institute of Medicine (2000) Dietary Reference Intakes for Vitamin C, Vitamin E, Selenium, and Carotenoids: A Report of the Panel on Dietary Antioxidants and Related Compounds, Subcommittees on Upper Reference Levels of Nutrients and of Interpretation and Use of Dietary Reference Intakes, and the Standing Committee on the Scientific Evaluation of Dietary Reference Intakes. Washington, DC: National Academy Press.

34. Wei W, Younghee MS \& Boudreau N (2001) Association of smoking with serum and dietary levels of antioxidants in adults: NHANES III, 1988-1994. Am J Public Health 91, 258-264.

35. Michaud DS, Giovannucci EL, Ascherio A, Rimm EB, Forman MR, Sampson L \& Willett WC (1998) Associations of plasma carotenoid concentrations and dietary intake of specific carotenoids in samples of two prospective cohort studies using a new carotenoid database. Cancer Epidemiol Biomarkers Prev 7, 283-290.

36. Stryker WS, Kaplan LA, Stein EA, Stampfer MJ, Sober A \& Willett WC (1988) The relation of diet, cigarette smoking, and alcohol consumption to plasma $\beta$-carotene and $\alpha$-tocopherol levels. Am J Epidemiol 127, 283-296.

37. Hebert JR, Hurley TG, Hsieh J, Rogers E, Stoddard AM, Sorensen G \& Nicolosi RJ (1994) Determinants of plasma vitamins and lipids: the Working Well Study. $A m J$ Epidemiol 140, 132-147.

38. Albanes D, Virtamo J, Taylor PR, Rautalahti M, Pirtinen P \& Heinonen OP (1997) Effects of supplemental $\beta$-carotene, cigarette smoking, and alcohol consumption on serum carotenoids in the Alpha-Tocopherol, Beta-Carotene Cancer Prevention Study. Am J Clin Nutr 66, 366-372.

39. Marangon K, Herbeth B, Lecomte E, Paul-Dauphin A, Grolier P, Chancerelle Y, Artur Y \& Siest G (1998) Diet, antioxidant status, and smoking habits in French men. $\mathrm{AmJ}$ Clin Nutr 50, 236-238.

40. Dietrich M, Block G, Norkus EP, Hudes M, Traber MG, Cross CE \& Paker L (2003) Smoking and exposure to environmental tobacco smoke decreases some plasma antioxidants and increase $\gamma$-tocopherol in vivo after adjustment for dietary antioxidant intakes. Am J Clin Nutr $77,160-166$.

41. Handelman GJ, Packer L \& Cross CE (1996) Destruction of tocopherols, carotenoids, and retinol in human plasma by cigarette smoke. Am J Clin Nutr 63, 559-565.

42. Berg G, Kohlmeier K \& Brenner H (1997) Use of oral contraceptives and serum $\beta$-carotene. Eur J Clin Nutr 51, 181-187. 
43. Nebeling LC, Forman MR, Graubard BI \& Snyder RA (1996) Specific and total carotenoid intakes among oral contraceptive and estrogen hormone users in the United States. J Am Coll Nutr 15, 608-613.

44. Simonetti P, Cestaro B, Porrini M, Viani P, Roggi C \& Testonli F (1993) Effect of alcohol intake on lipids and fatsoluble vitamins in blood. Minerva Med 84, 447-452.

45. Simonetti P, Brusamolino A, Pellegrini N, Clemente G, Roggi C \& Cestaro B (1995) Evaluation of the effect of alcohol consumption on erythrocyte lipids and vitamins in a healthy population. Alcohol Clin Exp Res 19, 517-522.

46. Cooney RV, Franke AA, Hankin JH, Custer LJ, Wilkens LR, Harwood PJ \& Le Marchand L (1995) Seasonal variation in plasma micronutrients and antioxidants. Cancer Epidemiol Biomarkers Prev 4, 207-215.

47. Giuliano AR, Siegel EM, Roe DJ et al. (2003) Dietary intake and risk of persistent human papillomavirus (HPV) infection: the Ludwig-McGill HPV natural history study. J Infect Dis 188, 1508-1516.

48. Brady H, Lamb MM, Sokol R, Ross CA, Seifer JA, Rewers N \& Norris JM (2007) Plasma micronutrients are associated with dietary intake and environmental tobacco smoke exposure in a paediatric population. Public Health Nutr 10 712-718

49. Block G, Dietrich M, Norkus E, Jensen C, Benowitz NL, Morrow JD, Hudes M \& Packer L (2006) Intraindividual variability of plasma antioxidants, markers of oxidative stress, C-reactive protein, cotinine, and other biomarkers. Epidemiology 17, 404-412.

50. Wang L, Gaziano JM, Norkus EP, Buring JE \& Sesso HD (2008) Associations of plasma carotenoids with risk factors and biomarkers related to cardiovascular disease in middle-aged and older women. Am J Clin Nutr 88, $747-754$.

\section{Appendix}

\section{Members of the Brazilian Investigation into Nutrition and Cervical Cancer Prevention (BRINCA) Study Team}

Marly A. Cardoso, Luciana Y. Tomita and Lana C. Almeida (Department of Nutrition, School of Public Health, University of São Paulo, Brazil); Adhemar Longatto Filho, Maria da Gloria Mattosinho de Castro Ferraz, Maria Lucia Utagawa and Luciana S. Aguiar (Pathology Department, Adolfo Lutz Institute, São Paulo, Brazil); Cecília Roteli-Martins (Hospital Leonor Mendes de Barros, São Paulo, Brazil); Ronaldo Lucio Rangel Costa (Instituto Brasileiro de Controle do Câncer, São Paulo, Brazil); Marcos Desidério Ricci (Hospital Perola Byngton, São Paulo, Brazil); Venâncio Avancini Ferreira Alves (Department of Pathology, School of Medicine, University of São Paulo, Brazil); Vânia D'Almeida (Health Science Department, Federal University of São Paulo, Brazil); Márcia A. Sperança and Anete M. Francisco-Bagnariolli (School of Medicine of Marília, Brazil); Luisa Lina Villa, Maria Cecília Costa, Maria Antonieta Avilla Andreoli, João Simão Pereira Sobrinho and José Carlos Mann Prado (Ludwig Institute for Cancer Research, São Paulo, Brazil); Eduardo L. Franco (Division of Cancer Epidemiology, McGill University, Montréal, Canada). 